\title{
The Course of Neuropathic Symptoms in Relation to Adjuvant Chemotherapy Among Elderly Patients With Stage III Colon Cancer
}

Citation for published version (APA):

van Erning, F. N., Janssen-Heijnen, M. L. G., Wegdam, J. A., Slooter, G. D., Wijsman, J. H., Vreugenhil, A., Beijers, T. A. J. M., van de Poll-Franse, L. V., \& Lemmens, V. E. P. P. (2017). The Course of Neuropathic Symptoms in Relation to Adjuvant Chemotherapy Among Elderly Patients With Stage III Colon Cancer: A Longitudinal Study. Clinical Colorectal Cancer, 16(3), 195-203.

https://doi.org/10.1016/j.clcc.2016.09.002

Document status and date:

Published: 01/09/2017

DOI:

10.1016/j.clcc.2016.09.002

Document Version:

Publisher's PDF, also known as Version of record

Document license:

Taverne

Please check the document version of this publication:

- A submitted manuscript is the version of the article upon submission and before peer-review. There can be important differences between the submitted version and the official published version of record.

People interested in the research are advised to contact the author for the final version of the publication, or visit the DOI to the publisher's website.

- The final author version and the galley proof are versions of the publication after peer review.

- The final published version features the final layout of the paper including the volume, issue and page numbers.

Link to publication

\footnotetext{
General rights rights.

- You may freely distribute the URL identifying the publication in the public portal. please follow below link for the End User Agreement:

www.umlib.nl/taverne-license

Take down policy

If you believe that this document breaches copyright please contact us at:

repository@maastrichtuniversity.nl

providing details and we will investigate your claim.
}

Copyright and moral rights for the publications made accessible in the public portal are retained by the authors and/or other copyright owners and it is a condition of accessing publications that users recognise and abide by the legal requirements associated with these

- Users may download and print one copy of any publication from the public portal for the purpose of private study or research.

- You may not further distribute the material or use it for any profit-making activity or commercial gain

If the publication is distributed under the terms of Article $25 \mathrm{fa}$ of the Dutch Copyright Act, indicated by the "Taverne" license above, 


\section{The Course of Neuropathic Symptoms in Relation to Adjuvant Chemotherapy Among Elderly Patients With Stage III Colon Cancer: A Longitudinal Study}

Felice N. van Erning, ${ }^{1,2}$ Maryska L.G. Janssen-Heijnen, ${ }^{3,4}$ Johannes A. Wegdam, ${ }^{5}$ Gerrit D. Slooter, ${ }^{6}$ Jan H. Wijsman, ${ }^{7}$ Art Vreugenhil, ${ }^{8,9}$ Tonneke A.J.M. Beijers, ${ }^{8}$ Lonneke V. van de Poll-Franse, ${ }^{1,10}$ Valery E.P.P. Lemmens ${ }^{1,2}$

\section{Abstract}

The course of neuropathic symptoms among elderly patients with stage III colon cancer treated with CAPOX (capecitabine, oxaliplatin), capecitabine, or no chemotherapy was investigated. A total of 117 patients (76\%) selected from the Netherlands Cancer Registry completed the first questionnaire. The course of several sensory symptoms was less favorable for patients treated with chemotherapy. Moreover, CAPOX was associated with more symptoms in the toes and feet than was capecitabine.

Introduction: Among the elderly, the impairment of functional capacities due to neuropathy can have a significant impact. The aim of the present study was to investigate the course of neuropathic symptoms among elderly patients with stage III colon cancer treated with CAPOX (capecitabine, oxaliplatin), capecitabine monotherapy, or no adjuvant chemotherapy. Materials and Methods: The Netherlands Cancer Registry was used to select patients with stage III colon cancer and aged $\geq 70$ years. Questionnaires were sent after resection (T1) and 6 (T2) and 12 months (T3) later. Neuropathy was measured using the European Organization for Research and Treatment of Cancer Quality of Life QuestionnaireChemotherapy-Induced Peripheral Neuropathy 20. Logistic generalized estimating equations analyses were used to evaluate the effect of chemotherapy on the course of neuropathic symptoms. Results: Of 155 eligible patients, $117(76 \%)$ completed the T1 questionnaire, and 69 and 59 completed the T2 and T3 questionnaires, respectively. The course of the sensory symptoms tingling fingers or hands, tingling toes or feet, numbness in fingers or hands, and numbness in toes or feet was significantly unfavorable for patients treated with adjuvant chemotherapy (CAPOX or capecitabine) compared with that for patients who had not received adjuvant chemotherapy. The course of numbness in toes or feet also differed significantly between patients treated with CAPOX (T1, 7\%; T2, 50\%; T3, 42\%) and patients treated with capecitabine ( $\mathrm{T} 1$, 17\%; T2, 31\%; T3, 8\%). Additionally, patients treated with capecitabine reported significantly less tingling toes or feet (T1, $6 \%$; T2, 25\%; T3, 7\%) compared with patients treated with CAPOX (T1, 0\%; T2, 50\%; T3, 58\%). Conclusion: The course of several sensory symptoms over time was less favorable for elderly patients with colon cancer treated with chemotherapy. Moreover, CAPOX was associated with more symptoms in toes and feet compared with capecitabine. It is important to inform patients of these risks to enable informed decision-making.

Clinical Colorectal Cancer, Vol. 16, No. 3, 195-203 @ 2016 Elsevier Inc. All rights reserved.

Keywords: Capecitabine, Neuropathy, Numbness, Oxaliplatin, Tingling

\footnotetext{
${ }^{1}$ Department of Research, Netherlands Comprehensive Cancer Organisation, Eindhoven, the Netherlands

${ }^{2}$ Department of Public Health, Erasmus Medical Center, Rotterdam, the Netherlands

${ }^{3}$ Department of Clinical Epidemiology, VieCuri Medical Centre, Venlo, the Netherlands

${ }^{4}$ Department of Epidemiology, School for Oncology and Developmental Biology,

Maastricht University, Maastricht, the Netherlands

${ }^{5}$ Department of Surgery, Elkerliek Hospital, Helmond, the Netherlands

${ }^{6}$ Department of Surgery, Máxima Medical Centre, Veldhoven, the Netherlands ${ }^{7}$ Department of Surgery, Amphia Hospital, Breda, the Netherlands
}

\footnotetext{
${ }^{8}$ Department of Internal Medicine, Máxima Medical Centre, Veldhoven, the Netherland ${ }^{9}$ Department of Medical Oncology, Maastricht University Medical Centre, Maastricht, the Netherlands

${ }^{10}$ Department of Psychosocial Research and Epidemiology, Netherlands Cancer Institute, Amsterdam, the Netherlands

Submitted: May 17, 2016; Accepted: Sep 8, 2016; Epub: Sep 17, 2016

Address for correspondence: Felice Neline van Erning, MSc, Netherlands Comprehensive Cancer Organisation, PO Box 231, Eindhoven 5600 AE, The Netherlands E-mail contact: f.vanerning@iknl.nl
} 


\section{Neuropathic Symptoms and Adjuvant Chemotherapy}

\section{Introduction}

The adjuvant treatment for patients with pathologic stage III colon cancer after resection of the primary tumor is chemotherapy (CTx). Oxaliplatin combined with a fluoropyrimidine (ie, capecitabine or 5-fluorouracil/leucovorin) is the standard regimen for these patients, although the benefit of oxaliplatin on recurrence-free and overall survival is uncertain in elderly patients. ${ }^{1-5}$ In the case of contraindications for oxaliplatin, adjuvant treatment should consist of capecitabine monotherapy (CapMono). ${ }^{6}$

CTx-induced peripheral neuropathy (CIPN) is increasingly recognized as an important toxicity that compromises treatment plans. Although peripheral neuropathy is a very rare complication of capecitabine, ${ }^{7}$ it is a common adverse effect of oxaliplatin. Oxaliplatin can cause both an acute, mainly cold-triggered, neuropathy and a chronic neuropathy. ${ }^{8,9}$ Symptoms can differ: most symptoms are sensory, although motor and autonomic dysfunction can also occur. ${ }^{10,11}$ In general, acute neuropathy is characterized by paresthesia and dysesthesia of the hands and feet and reverses within a week, while chronic neuropathy mainly consists of symptoms of hypoesthesia and is only partly reversible. ${ }^{9,12,13}$ Acute neuropathy occurs in $80 \%$ to $90 \%$ of patients treated with oxaliplatin, ${ }^{10,14-16}$ and chronic neuropathy affects $30 \%$ to $60 \%$ of patients. ${ }^{10,15}$

The prevention and treatment of CIPN remain difficult. ${ }^{17}$ Because CIPN interferes with many aspects of daily life and is negatively associated with health-related quality of life, this is of major concern. ${ }^{18,19}$ Particularly for the growing population of elderly patients, the impairment of functional capacities can have a significant effect on their lives. Having information about the effects of different CTx regimens on neuropathic symptoms can help patients and clinicians in deciding on a suitable treatment course.

The aim of the present study was to gain insight into any differences in the course of neuropathic symptoms among elderly patients with stage III colon cancer subsequently treated with a combination of capecitabine and oxaliplatin (CAPOX), CapMono, or no adjuvant $\mathrm{CTx}$ in daily clinical practice. First, the interaction between treatment and time was investigated. Subsequently, the main effect of treatment on neuropathic symptoms was investigated. We expected that patients treated with CAPOX would experience neuropathic symptoms more often and that the course of their symptoms would be less favorable than that of patients treated with CapMono or no CTx.

\section{Materials and Methods Data Collection and Study Population}

Data were collected within the PROFILES database (Patient Reported Outcomes Following Initial treatment and Long-term Evaluation of Survivorship). ${ }^{20}$ PROFILES is linked to clinical data from the population-based Netherlands Cancer Registry (NCR). The NCR records the data for all patients with newly diagnosed cancer in the Netherlands. Information on patient and tumor characteristics, diagnosis, and treatment is routinely extracted from the medical records by trained administrators of the NCR. The anatomic tumor site is registered according to the International Classification of Diseases-Oncology. The pathologic TNM classification is used for staging of the primary tumor, according to the edition valid at the cancer diagnosis. Socioeconomic status (SES), based on individual fiscal data on the economic value of the home and household income, is provided at an aggregated level for each postal code. The number of comorbid conditions at time of cancer diagnosis is registered using a slightly modified version of the Charlson comorbidity index.

The NCR was used to identify patients with stage III (pT1-T4N1-N2M0) colon cancer aged $\geq 70$ years who had undergone resection. Questionnaire data were collected for patients with cancer diagnosed in 9 hospitals in the southeastern part of the Netherlands from March 2013 to October 2014. The treating physicians verified the status of each eligible patient before the patient was approached for study participation (eg, patients with serious cognitive impairment were excluded). All eligible patients received an invitation letter from their attending surgeon and both a paper questionnaire and a login account and password to complete the survey online. After 2 weeks, reminders were sent to patients who had not responded to the survey. The first questionnaire was sent after resection (T1), and the respondents received subsequent questionnaires 6 months (T2) and 12 months (T3) later.

A certified medical ethics committee approved the present study, and all patients provided written informed consent for participation in the study and agreed to the linkage of the questionnaire data with the sociodemographic and clinical information in the NCR.

\section{Study Measures}

Peripheral neuropathy was measured using the European Organization for Research and Treatment of Cancer quality of life questionnaire-chemotherapy-induced peripheral neuropathy 20 (EORTC QLQ-CIPN20), ${ }^{21}$ which contains 20 items assessing sensory, motor, and autonomic symptoms. All items are measured using a 4-point Likert scale ranging from 1 (not at all) to 4 (very much).

Diabetes, osteoarthritis, and rheumatoid arthritis are comorbid conditions known to be associated with neuropathy-like symptoms. The presence of these conditions at completion of the first questionnaire was self-reported by the patients and assessed using the adapted self-administered comorbidity questionnaire. ${ }^{22}$

\section{Statistical Analysis}

Differences in the characteristics between the respondents and nonrespondents were assessed using $\chi^{2}$ tests and Fisher's exact tests, as appropriate. Differences between respondents completing 1 questionnaire and respondents completing $\geq 2$ questionnaires and differences between respondents treated with CAPOX, CapMono, or no CTx were analyzed similarly.

For the group of respondents subsequently treated with CAPOX, CapMono, or no CTx, the number and percentage of patients who experienced mild to severe neuropathic symptoms at T1 were reported per individual item of the EORTC QLQCIPN20. The severity of neuropathic symptoms was dichotomized as in a previous report ${ }^{23}$ as follows: the response categories "a little," "quite a bit," and "very much" were grouped as mild to severe neuropathic symptoms and the response category "not at all" as no neuropathic symptoms. Multivariable logistic regression analyses were performed to evaluate differences between treatment groups in the proportion of patients reporting mild to severe 
neuropathy symptoms at T1. Adjustments were made for age category (70-74, 75-79, and $\geq 80$ years) and the presence of osteoarthritis and diabetes.

For the subgroup of patients completing $\geq 2$ questionnaires and treated with CAPOX, CapMono, or no CTx, the number and percentages of patients who experienced mild to severe neuropathic symptoms at T1, T2, and T3 were reported per individual item of the EORTC QLQ-CIPN20. Because neuropathic symptoms were repeatedly measured in the same patients, and observations of 1 patient were not independent of each other, logistic generalized estimating equation (GEE) analyses with an exchangeable correlation structure were used. Both the interaction between treatment and time (ie, T1 to T2 to T3) and the main effect of treatment on neuropathic symptoms were evaluated. First, the interaction between the receipt of CTx (yes vs. no, regardless of regimen) and time was evaluated. Second, the interaction between the CTx regimen received and time

\section{Figure 1 Flowchart of the Data Collection Process}

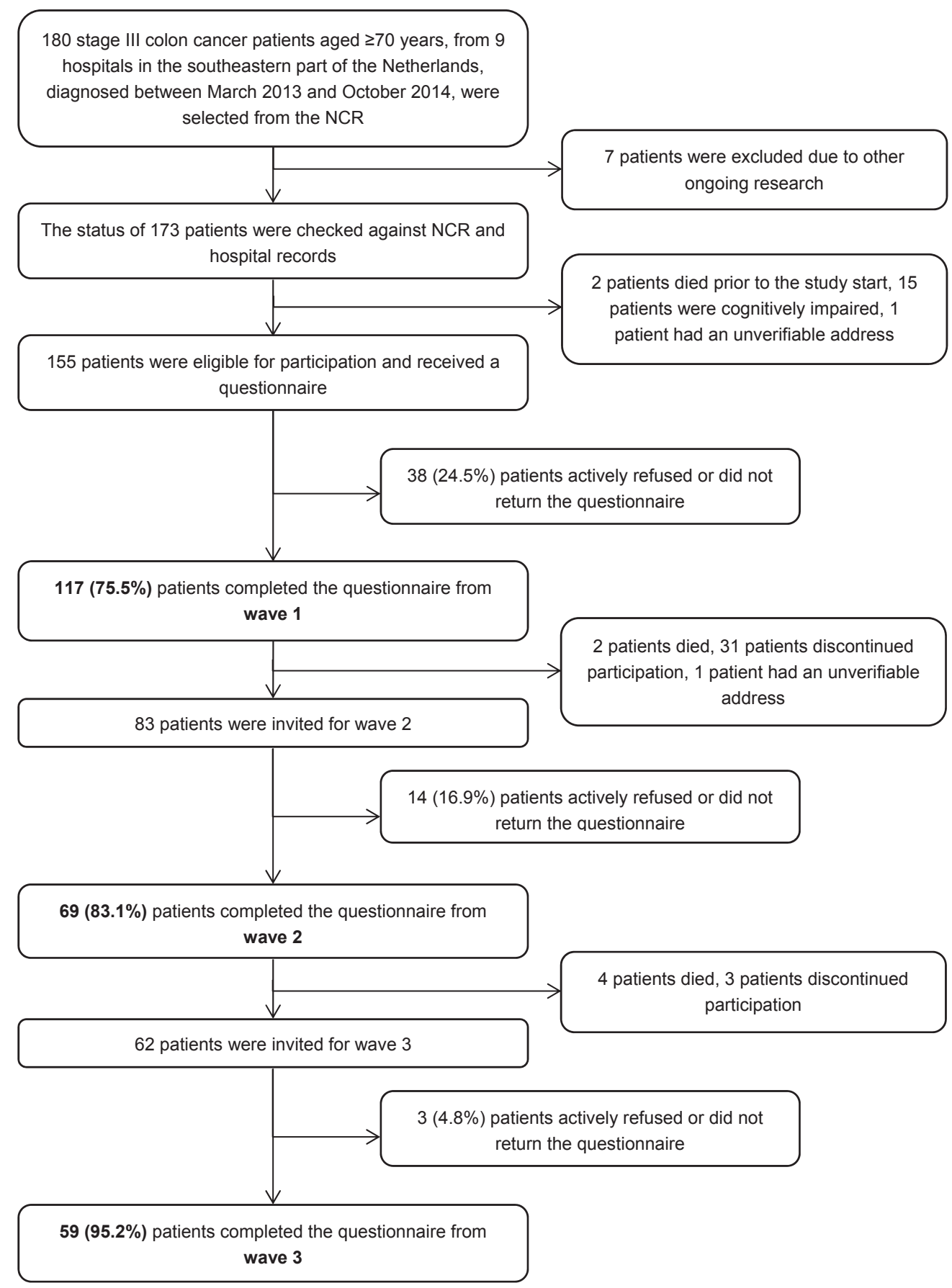


was assessed. In all logistic GEE analyses, adjustments were also made for time, age category, osteoarthritis, and diabetes.

$P<.05$ was considered statistically significant. SAS/STAT statistical software (SAS system, version 9.4; SAS Institute, Cary, NC) was used for all analyses.

\section{Results}

\section{Study Population}

Of the 155 elderly patients with stage III colon cancer eligible for participation, 117 completed the first questionnaire (T1), resulting in a response rate of $76 \%$. Subsequently, 69 patients completed the second questionnaire (T2) and 59 patients, the third questionnaire (T3; Figure 1).

No significant differences between the respondents and nonrespondents were present, except for older age at the cancer diagnosis among the nonrespondents (Table 1). For the respondents, the mean interval between the date of resection of the primary tumor and the date of completing the first questionnaire was $40 \pm 18$ days. Additionally, among the respondents treated with adjuvant CTx, $88 \%$ completed the first questionnaire before or during cycle 1 and $12 \%$ during cycle 2 . The patients receiving CAPOX were younger than those receiving CapMono or no CTx, and the patients treated without CTx more often had osteoarthritis compared with those receiving CAPOX or CapMono (Table 2).

Analyses between the respondents who completed 1 and those who completed $\geq 2$ questionnaires showed no significant differences in gender, age, SES, number of comorbid conditions, diabetes, or adjuvant treatment (data not shown). Osteoarthritis was less common among respondents completing $\geq 2$ questionnaires than among respondents completing 1 questionnaire (19\% vs. $35 \%$; $P=.0434)$.

\section{Neuropathic Symptoms Present at Baseline (T1)}

Among the group of $\mathrm{T} 1$ respondents subsequently treated with CAPOX, CapMono, or no CTx, the neuropathy symptoms that bothered $>20 \%$ of the patients at baseline included trouble getting or maintaining an erection ( $80 \%$ of men), trouble opening a jar or bottle due to loss of strength in hands (36\%), trouble walking stairs or standing up from a chair due to weakness in legs (29\%), trouble handling small objects (eg, buttoning a blouse; 27\%), trouble hearing (25\%), dizziness after standing up (25\%), and tingling fingers or hands (24\%).

After adjustment for age category, osteoarthritis and diabetes, patients (subsequently) treated with CAPOX less often reported trouble walking stairs or standing up from a chair due to weakness in legs compared with patients (subsequently) treated with CapMono (crude percentages, $7 \%$ vs. $36 \%$; adjusted $P=.0266$ ) and compared with patients who did not receive adjuvant $\mathrm{CTx}$ (crude percentages, $7 \%$ vs. $36 \%$; adjusted $P=.0418$; Table 3 ). No other differences were found among the groups.

\section{Course of Neuropathic Symptoms by Adjuvant Treatment (T1-T2-T3)}

The data from patients who completed $\geq 2$ questionnaires are listed in Table 4, which includes an overview of the number and percentages of patients who reported mild to severe neuropathic symptoms at T1, T2, and T3 by adjuvant treatment.
Table 1 Characteristics of Respondents (Completing $\geq 1$ Questionnaire) and Nonrespondents

\begin{tabular}{|c|c|c|c|}
\hline Characteristic & $\begin{array}{c}\text { Respondents } \\
(\mathrm{n}=117 ; 76 \%)\end{array}$ & $\begin{array}{c}\text { Nonrespondents } \\
(n=38 ; 24 \%)\end{array}$ & $P$ Value $^{\mathrm{a}}$ \\
\hline Gender & & & .6043 \\
\hline Male & $58(50)$ & $17(45)$ & \\
\hline Female & $59(50)$ & $21(55)$ & \\
\hline $\mathrm{Age}^{\mathrm{b}}$ (years) & & & .0417 \\
\hline $70-74$ & $32(27)$ & $13(34)$ & \\
\hline $75-79$ & $44(38)$ & $6(16)$ & \\
\hline$\geq 80$ & $41(35)$ & $19(50)$ & \\
\hline Socioeconomic status & & & .4562 \\
\hline Low & $29(25)$ & $11(29)$ & \\
\hline Intermediate & $41(35)$ & $14(36)$ & \\
\hline High & $28(24)$ & $11(29)$ & \\
\hline Institutions & $4(3)$ & $1(3)$ & \\
\hline Unknown & $15(13)$ & $1(3)$ & \\
\hline Comorbid conditions ${ }^{\mathrm{b}}$ & & & .1278 \\
\hline 0 & $18(15)$ & $5(13)$ & \\
\hline 1 & $37(32)$ & $7(18)$ & \\
\hline$\geq 2$ & $62(53)$ & $25(66)$ & \\
\hline Unknown & $0(0)$ & $1(3)$ & \\
\hline Adjuvant chemotherapy & & & .5290 \\
\hline None & $58(50)$ & $18(47)$ & \\
\hline $\begin{array}{l}\text { Capecitabine plus } \\
\text { oxaliplatin }\end{array}$ & $27(23)$ & $7(18)$ & \\
\hline $\begin{array}{l}\text { Capecitabine } \\
\text { monotherapy }\end{array}$ & $28(24)$ & $13(34)$ & \\
\hline Other & $4(3)$ & $0(0)$ & \\
\hline
\end{tabular}

Data presented as $n(\%)$.

asignificance of $\chi^{2}$ test or Fisher's exact test, as appropriate.

${ }^{b}$ At cancer diagnosis.

Logistic GEE analyses showed a significant interaction between the receipt of CTx (yes vs. no) and time (T1, T2, T3) for the items tingling fingers or hands $(P=.0017)$, tingling toes or feet $(P=$ $.0060)$, numbness in fingers or hands $(P=.0118)$, and numbness in toes or feet $(P=.0073)$. This indicates that the course of these neuropathic symptoms differed between patients treated with and without CTx. Additionally, for the item numbness in toes or feet, a significant interaction was present between CTx regimen and time $(P=.0152)$, indicating that the course of this symptom differed between patients receiving CAPOX and patients receiving CapMono. A graph of these 4 sensory neuropathic symptoms is depicted in Figure 2.

In the subgroup of patients receiving CTx, a main effect of CTx regimen was found for the item tingling toes or feet $(P=.0199)$ : patients receiving CapMono had a lower odds of reporting tingling toes or feet compared with patients receiving CAPOX (odds ratio, 0.18; 95\% confidence interval, 0.04-0.76).

For all other neuropathic symptoms, no significant interaction between adjuvant treatment and time was found, indicating that the course of these neuropathic symptoms over time was similar among the treatment groups. 


\begin{tabular}{|c|c|c|c|c|}
\hline Characteristic & CAPOX (n = 27; 24\%) & CapMono (n = 28; 25\%) & $\begin{array}{c}\text { No Adjuvant CTx } \\
(\mathrm{n}=58 ; 51 \%)\end{array}$ & $P$ Value $^{\mathrm{a}}$ \\
\hline Gender & & & & .4315 \\
\hline Male & $16(59)$ & $15(54)$ & $26(45)$ & \\
\hline Female & $11(41)$ & $13(46)$ & $32(55)$ & \\
\hline $\mathrm{Age}^{\mathrm{b}}$ (years) & & & & $<.0001$ \\
\hline $70-74$ & $16(59)$ & $6(22)$ & $6(10)$ & \\
\hline $75-79$ & $9(33)$ & $11(39)$ & $24(42)$ & \\
\hline$\geq 80$ & $2(8)$ & $11(39)$ & $28(48)$ & \\
\hline Socioeconomic status & & & & .7329 \\
\hline Low & $7(26)$ & $10(36)$ & $12(21)$ & \\
\hline Intermediate & $10(37)$ & $10(36)$ & 18 (31) & \\
\hline High & $7(26)$ & $5(18)$ & $16(27)$ & \\
\hline Institutions & $0(0)$ & $0(0)$ & $4(7)$ & \\
\hline Unknown & $3(11)$ & $3(10)$ & 8 (14) & \\
\hline Comorbid conditions $^{b}$ & & & & .0606 \\
\hline 0 & $7(26)$ & $2(7)$ & $8(14)$ & \\
\hline 1 & $10(37)$ & $5(18)$ & $20(34)$ & \\
\hline$\geq 2$ & $10(37)$ & $21(75)$ & 30 (52) & \\
\hline Diabetes $^{\mathrm{C}}$ & & & & .3763 \\
\hline No & $24(89)$ & $21(75)$ & $48(83)$ & \\
\hline Yes & $3(11)$ & $7(25)$ & 10 (17) & \\
\hline Osteoarthritis ${ }^{\mathrm{C}}$ & & & & .0148 \\
\hline No & 24 (89) & $24(86)$ & 37 (64) & \\
\hline Yes & $3(11)$ & $4(14)$ & $21(36)$ & \\
\hline
\end{tabular}

Data presented as $\mathrm{n}(\%)$.

Abbreviations: CapMono = capecitabine monotherapy; CAPOX = capecitabine plus oxaliplatin; CTx = chemotherapy.

asignificance of $\chi^{2}$ test or Fisher's exact test, as appropriate.

${ }^{\mathrm{b}}$ At cancer diagnosis.

${ }^{\mathrm{C}}$ At completion of first questionnaire.

\section{Discussion}

The present longitudinal study of elderly patients with stage III colon cancer showed that the course of several sensory symptoms (ie, tingling and numbness in fingers or hands and toes or feet) is less favorable for patients receiving adjuvant CTx compared with patients who did not receive adjuvant CTx. We also found that patients treated with CAPOX more often reported tingling toes or feet than patients treated with CapMono.

Because peripheral neuropathy is a very rare complication of capecitabine, ${ }^{7}$ we were surprised that the course of some sensory symptoms was less favorable for all patients receiving adjuvant CTx, regardless of whether the patients had received CAPOX or CapMono. A possible explanation might be found in another toxicity often caused by capecitabine, palmar-plantar erythrodysesthesia or hand-foot syndrome (HFS). ${ }^{24}$ The initial symptoms of HFS are dysesthesia and tingling in the palms, fingers, and soles of the feet. These symptoms can progress within a few days to burning pain with erythema and swelling. ${ }^{25-28}$ The symptoms caused by HFS are therefore partly comparable to the symptoms caused by neuropathy. We expect that patients treated with CapMono reported these complaints on the questionnaires.
The finding that patients treated with CAPOX more often reported tingling toes or feet than patients treated with CapMono could have been because in HFS, the palms of the hands are more frequently affected than the soles of the feet. ${ }^{25,26,28}$ Additionally, another study that used the EORTC QLQ-CIPN20 sensory subscale to measure CIPN reported more numbness, tingling, and burning pain in the toes or feet than in the fingers or hands. ${ }^{29}$

Studies on patient-reported neuropathic symptoms are limited. In the XELOXA (oxaliplatin combined with capecitabine [XELOX] in adjuvant colon cancer treatment) trial, neuropathic symptoms were monitored and graded according to the National Cancer Institute Common Toxicity Criteria for Adverse Events. ${ }^{30}$ All grade neurosensory toxicity was common (78\%) but mild to moderate in severity (ie, $10 \%-12 \%$ had grade III-IV) among patients treated with CAPOX. ${ }^{30}$ In the National Surgical Adjuvant Breast and Bowel Project C-07 trial, self-reported neurotoxicity was included for a subgroup of the trial population and measured using the Functional Assessment of Cancer Therapy/Gynecologic Oncology Group Oxaliplatin-specific Neurotoxicity questionnaire. ${ }^{31}$ Among patients without symptoms at baseline, the most often reported symptoms during the second cycle of treatment with oxaliplatin were cold-induced pain in the hands and feet 


\begin{tabular}{|c|c|c|c|c|c|}
\hline \multirow[b]{2}{*}{ Variable } & \multirow[b]{2}{*}{ CAPOX } & \multirow[b]{2}{*}{ CapMono } & \multirow[b]{2}{*}{$\begin{array}{c}\text { No Adjuvant } \\
\text { CTx }\end{array}$} & \multicolumn{2}{|c|}{$P$ Value $^{\mathrm{b}}$} \\
\hline & & & & $\begin{array}{l}\text { CAPOX vs. } \\
\text { CapMono }\end{array}$ & $\begin{array}{l}\text { CAPOX vs. No } \\
\text { Adjuvant CTx }\end{array}$ \\
\hline \multicolumn{6}{|l|}{ Sensory symptoms and problems } \\
\hline Tingling fingers or hands & $9(33)$ & $3(11)$ & $15(26)$ & .2056 & .4392 \\
\hline Tingling toes or feet & $5(19)$ & $2(7)$ & $8(14)$ & .5159 & .5188 \\
\hline Numbness in fingers or hands & $1(4)$ & $4(15)$ & $11(20)$ & .0784 & .0527 \\
\hline Numbness in toes or feet & $3(11)$ & $5(18)$ & $12(21)$ & .2827 & .1398 \\
\hline Aching or burning pain in finger or hands & $1(4)$ & $2(7)$ & $3(5)$ & .7081 & .9969 \\
\hline Aching or burning pain in toes or feet & $2(7)$ & $2(7)$ & $3(5)$ & .6855 & .3989 \\
\hline Trouble standing or walking & $2(7)$ & $4(15)$ & $12(21)$ & .8127 & .3712 \\
\hline Trouble distinguishing hot and cold water & $0(0)$ & $0(0)$ & $5(9)$ & NA & NA \\
\hline Trouble hearing & $4(15)$ & $7(26)$ & $17(30)$ & .3760 & .2338 \\
\hline \multicolumn{6}{|l|}{ Motor scale } \\
\hline Cramps in hands & $3(11)$ & $4(15)$ & $10(18)$ & .5002 & .4186 \\
\hline Cramps in feet & $1(4)$ & $4(15)$ & $13(22)$ & .3300 & .2555 \\
\hline Trouble holding a penmaking writing difficult & $2(7)$ & $1(4)$ & $11(19)$ & .6188 & .1180 \\
\hline Trouble handling small objects (eg, buttoning a blouse) & $5(19)$ & $7(25)$ & $18(31)$ & .6450 & .3934 \\
\hline Trouble opening jar/bottle due to loss of strength in hands & $7(26)$ & $11(39)$ & $22(39)$ & .2026 & .2994 \\
\hline Trouble walking because feet come down too hard & $0(0)$ & $1(4)$ & $8(14)$ & NA & NA \\
\hline $\begin{array}{l}\text { Trouble walking stairs or standing up from a chair due to } \\
\text { weakness in legs }\end{array}$ & $2(7)$ & $10(36)$ & $20(36)$ & .0266 & .0418 \\
\hline Only for those driving: trouble driving due to use of pedals & $1(7)$ & $2(13)$ & $2(8)$ & .4504 & .5762 \\
\hline \multicolumn{6}{|l|}{ Autonomic scale } \\
\hline Dizziness after standing up & $5(19)$ & $5(18)$ & $18(32)$ & .8791 & .3273 \\
\hline Blurry vision & $4(15)$ & $4(14)$ & $11(19)$ & .7814 & .4828 \\
\hline Only for males: trouble getting or maintaining an erection & $5(83)$ & $8(89)$ & $11(73)$ & .7240 & .7263 \\
\hline
\end{tabular}

Data presented as $\mathrm{n}(\%)$

Abbreviations: CapMono = capecitabine monotherapy; CAPOX = capecitabine plus oxaliplatin; $\mathrm{CTX}=$ chemotherapy; NA = not applicable (numbers too small to calculate $P$ value)

"Mild to severe symptoms reflect the response categories: "a little," quite a bit," and "very much."

${ }^{\mathrm{b}} P$ values from logistic regression analyses showing differences adjusted for age category, osteoarthritis, and diabetes.

(severity, "quite a bit" or "very much" for 26\%) and hand numbness or tingling (20\%). By 6 months after the start of CTx, the incidence of cold-induced hand/foot pain had diminished (8\%) but that of hand numbness/tingling remained high (17\%), and the incidence of foot numbness/tingling (17\%) and foot discomfort $(10 \%)$ had increased. Foot numbness/tingling remained high (14\%) after 18 months. ${ }^{31}$ In that trial, oxaliplatin was administered in a regimen with 5-fluorouracil, instead of the oral analogue capecitabine. Another study showed that although the incidence of acute neuropathy seemed comparable between CAPOX and FOLFOX, chronic peripheral neuropathy appeared to be more common with CAPOX. ${ }^{15}$

In contrast to previous studies on patient-reported neuropathic symptoms, only patients aged $\geq 70$ years were included in the present study. A comparison of the neuropathic symptoms reported in our study with those reported by younger patient population would be valuable to establish whether the elderly experience neuropathic symptoms to a smaller, similar, or greater extent. Unfortunately, data for a direct comparison are not available. However, the symptoms reported in our study were similar to those reported in earlier studies, suggesting that the elderly experience neuropathic symptoms comparable to that of their younger counterparts, although comparisons are difficult because these studies included patients 2 to 11 years after diagnosis and the data were not longitudinal. ${ }^{32,33}$

The present study also showed that at baseline several neuropathic symptoms were already present and bothered $>20 \%$ of the patients. These symptoms were in the sensory, motor, and autonomic domains. Previous research has shown that subclinical peripheral neuropathy is a common finding in patients with colorectal cancer prior to $\mathrm{CTx}$, indicating that the cancer itself is a contributing factor. ${ }^{34}$ Moreover, many symptoms could also be related to the aging process, instead of the cancer or its treatment. ${ }^{35}$ With the exception of weakness in the legs, which was less often reported by patients treated with CAPOX, no differences in symptoms were found at T1 among the treatment groups. That the patients treated with CAPOX were younger and less often had osteoarthritis suggests that confounding by indication might have played a role.

Previous studies have shown that the benefit of oxaliplatin on recurrence-free and overall survival is uncertain in elderly patients 


\begin{tabular}{|c|c|c|c|c|c|c|c|c|c|}
\hline \multirow[b]{2}{*}{ Variable } & \multicolumn{3}{|c|}{ CAPOX } & \multicolumn{3}{|c|}{ CapMono } & \multicolumn{3}{|c|}{ No Adjuvant CTx } \\
\hline & T1 & T2 & T3 & T1 & T2 & T3 & T1 & T2 & T3 \\
\hline \multicolumn{10}{|l|}{ Sensory symptoms and problems } \\
\hline Tingling fingers or hands & $3(21)$ & $10(71)$ & $6(50)$ & $2(11)$ & $7(44)$ & $4(29)$ & $9(27)$ & $7(22)$ & $11(38)$ \\
\hline Tingling toes or feet & $0(0)$ & $7(50)$ & $7(58)$ & $1(6)$ & $4(25)$ & $1(7)$ & $7(21)$ & $6(19)$ & $6(21)$ \\
\hline Numbness in fingers or hands & $0(0)$ & $9(64)$ & $5(42)$ & $3(19)$ & $6(38)$ & $3(21)$ & $5(16)$ & $8(25)$ & $9(31)$ \\
\hline Numbness in toes or feet & $1(7)$ & $7(50)$ & $5(42)$ & $3(17)$ & $5(31)$ & $1(8)$ & $9(26)$ & $7(22)$ & $13(45)$ \\
\hline Aching or burning pain in finger or hands & $1(7)$ & $1(7)$ & $1(8)$ & $1(6)$ & $3(19)$ & $2(14)$ & $2(6)$ & $2(6)$ & $4(14)$ \\
\hline Aching or burning pain in toes or feet & $1(7)$ & $3(21)$ & $2(17)$ & $1(6)$ & $4(25)$ & $3(21)$ & $2(6)$ & $6(19)$ & $5(17)$ \\
\hline Trouble standing or walking & $0(0)$ & $6(43)$ & $3(25)$ & $2(11)$ & $4(25)$ & $2(14)$ & $6(18)$ & $8(24)$ & $7(24)$ \\
\hline Trouble distinguishing hot and cold water & $0(0)$ & $4(29)$ & $4(33)$ & $0(0)$ & $1(6)$ & $1(7)$ & $3(9)$ & $1(3)$ & $2(7)$ \\
\hline Trouble hearing & $0(0)$ & $1(7)$ & $1(8)$ & $4(24)$ & $8(47)$ & $3(21)$ & $9(27)$ & $13(39)$ & $11(37)$ \\
\hline \multicolumn{10}{|l|}{ Motor scale } \\
\hline Cramps in hands & $0(0)$ & $0(0)$ & $3(25)$ & $3(17)$ & $4(24)$ & $4(29)$ & $5(16)$ & $9(28)$ & $9(31)$ \\
\hline Cramps in feet & $0(0)$ & $0(0)$ & $3(25)$ & $2(12)$ & $4(24)$ & $6(43)$ & $8(24)$ & $15(47)$ & $11(37)$ \\
\hline Trouble holding a pen making writing difficult & $0(0)$ & $5(36)$ & $5(42)$ & $1(6)$ & $2(12)$ & $1(7)$ & $7(21)$ & $6(19)$ & $5(17)$ \\
\hline Trouble handling small objects (eg, buttoning a blouse) & $2(14)$ & $8(57)$ & $7(58)$ & $4(22)$ & $7(41)$ & $5(36)$ & $11(32)$ & $12(36)$ & $13(43)$ \\
\hline Trouble opening jar/bottle due to loss of strength in hands & $3(21)$ & $7(50)$ & $4(33)$ & $7(39)$ & $10(59)$ & $6(43)$ & $11(33)$ & $10(30)$ & $12(40)$ \\
\hline Trouble walking because feet come down too hard & $0(0)$ & $1(7)$ & $0(0)$ & $0(0)$ & $2(13)$ & $1(7)$ & $6(18)$ & 7 (22) & $6(20)$ \\
\hline $\begin{array}{l}\text { Trouble walking stairs or standing up from a chair due to } \\
\text { weakness in legs }\end{array}$ & $1(7)$ & $4(29)$ & $5(42)$ & $6(33)$ & $7(41)$ & $5(36)$ & $11(33)$ & $13(39)$ & $13(43)$ \\
\hline Only for those driving: trouble driving due to use of pedals & $0(0)$ & $1(11)$ & $0(0)$ & $1(9)$ & $0(0)$ & $0(0)$ & $1(6)$ & $2(10)$ & $1(5)$ \\
\hline \multicolumn{10}{|l|}{ Autonomic scale } \\
\hline Dizziness after standing up & $2(14)$ & $2(14)$ & $2(17)$ & $3(17)$ & $2(13)$ & $3(21)$ & $10(30)$ & $11(34)$ & $9(30)$ \\
\hline Blurry vision & $1(7)$ & $5(36)$ & $1(8)$ & $3(17)$ & $6(35)$ & $3(21)$ & $7(21)$ & $7(22)$ & $6(21)$ \\
\hline Only for males: trouble getting or maintaining an erection & $2(67)$ & $4(67)$ & $3(100)$ & $7(100)$ & $7(100)$ & $6(86)$ & $8(67)$ & 10 (91) & $10(100)$ \\
\hline
\end{tabular}

Data presented as $\mathrm{n}(\%)$.

Abbreviations: CapMono = capecitabine monotherapy; CAPOX = capecitabine plus oxaliplatin; CTx = chemotherapy; $11=$ first questionnaire sent (after resection); $\mathrm{T} 2=$ second questionnaire sent 6 months after first; T3 = second questionnaire sent 12 months after first questionnaire.

aild to severe symptoms reflect the response categories "a little," "quite a bit," and "very much."

with stage III colon cancer. ${ }^{1-5}$ To help clinicians and patients decide on a desirable course of treatment, not only is information on the survival benefit associated with different treatment regimens important, but also information on the possible short- and long-term side effects. CIPN might impair functional capacities and affect healthrelated quality of life, both during and after adjuvant treatment. ${ }^{18,19}$ Neuropathy is only partly reversible and, as also shown in previous research, chronic neuropathy will still be present in many patients $\geq 1$ years after the termination of therapy. ${ }^{12}$ Even as long as 11 years after diagnosis, neuropathic symptoms have still been reported by colorectal cancer patients, especially sensory symptoms in the toes and feet among those treated with oxaliplatin. ${ }^{32}$ As the effect of oxaliplatin on survival is uncertain among the elderly and the results of the present study indicate that the elderly treated with CAPOX compared with CapMono reported more sensory symptoms in the toes and feet that are known to persist long term, the addition of oxaliplatin might not be justified. At the very least, the present results do not provide support for the addition of oxaliplatin to adjuvant CTx for elderly patients with stage III colon cancer.

Previous studies have shown that a greater cumulative dose of oxaliplatin seems to be a predictive factor for the development of chronic peripheral neuropathy. ${ }^{12,33}$ This chronic peripheral neuropathy occurs after a cumulative dose of $\sim 750$ to $800 \mathrm{mg} / \mathrm{m}^{2}$ of oxaliplatin. ${ }^{16}$ Unfortunately, the number of patients in our study was too small to perform analyses according to the cumulative dose received. The present study also had some other limitations. Although we achieved a high response rate at T1 despite the timing being shortly after major cancer surgery, the sample size at T2 and $\mathrm{T} 3$ was relatively small. At T1, in addition to informed consent, the patients were able to indicate that they discontinued participation for the next 2 questionnaires. It is conceivable that patients would have decided differently if asked after 6 months. Additionally, not all patients receiving adjuvant CTx had completed the first questionnaire before the start of adjuvant CTx. However, a large majority had completed the questionnaire before the start of the second cycle, during which the first toxicity might occur. ${ }^{16,36}$ It is possible that the differences were underestimated as a result. Furthermore, the scores for each item were dichotomized, thereby impeding the possibility to investigate differences in the severity of symptoms among the treatment groups. Previous research has shown that even low-grade toxicities can lead to treatment alterations in older patients. ${ }^{37}$ Another limitation was that we could not determine why 

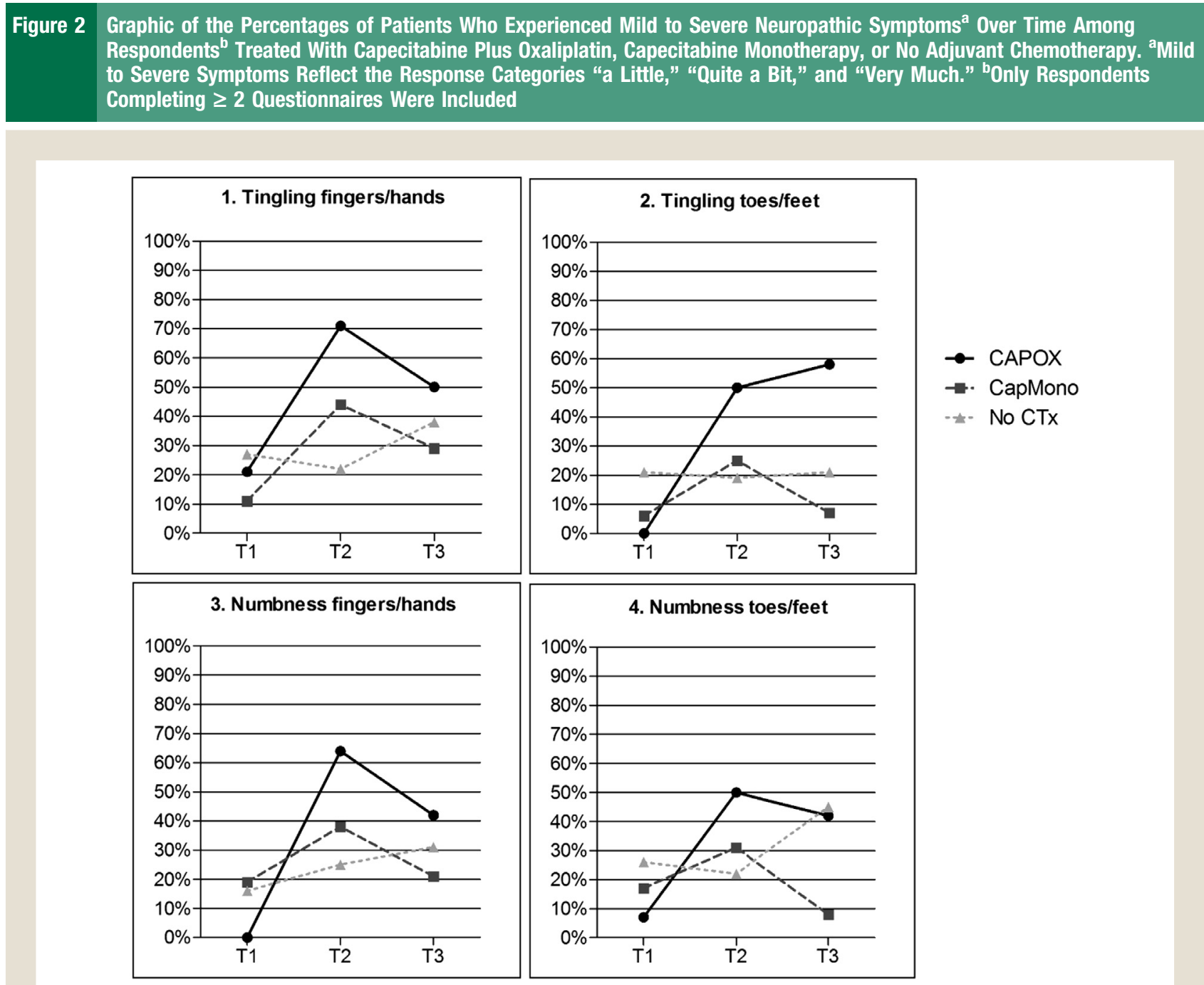

the nonrespondents declined participation. This could have resulted from the neuropathic symptoms or other problems. However, we were able to compare respondents and nonrespondents on sociodemographic and clinical characteristics and only found differences in age at the time of the cancer diagnosis.

Despite these limitations, the present study provides an important contribution to the limited data available on self-reported neuropathic symptoms according to CTx regimen among elderly patients with stage III colon cancer. The strong points of the present study include the longitudinal design with a baseline measurement and the adjustment for comorbid conditions (ie, osteoarthritis and diabetes) also associated with neuropathic symptoms. Although rheumatoid arthritis is also associated with neuropathy-like complaints, only 3 patients in our study had rheumatoid arthritis; therefore, no adjustments were made for this comorbid condition.

\section{Conclusions}

Our results have shown that the course of several sensory symptoms over time is less favorable for patients undergoing CTx. Additionally, patients treated with CAPOX more often reported symptoms in the toes and feet than did patients treated with CapMono. Although improving survival is important, evaluating the side effects of treatment will determine the functional effectiveness of the treatment. It is of paramount importance to inform patients of the risk of developing CIPN to enable patients to make informed decisions.

\section{Clinical Practice Points}

- To help clinicians and patients decide on a suitable treatment, not only is information on the survival benefit associated with different treatment regimens important, but also information on the possible short- and long-term side effects.

- Neuropathy is an important toxicity that interferes with many aspects of daily life. In particular, among the growing population of elderly patients, the impairment of functional capacities can have a significant effect on their lives.

- The present longitudinal study among elderly patients with stage III colon cancer showed that the course of the sensory symptoms, including tingling fingers or hands, tingling toes or feet, numbness in fingers or hands, and numbness in toes or feet, was 
significantly more unfavorable for patients receiving adjuvant CTx (CAPOX or CapMono) than for patients who did not receive adjuvant $\mathrm{CT} x$.

- The course of numbness in the toes and feet also differed significantly between patients treated with CAPOX and patients treated with CapMono. Additionally, patients treated with CapMono reported tingling toes and feet significantly less often than did patients treated with CAPOX.

- Because the effect of oxaliplatin on survival is uncertain among elderly stage III colon cancer patients and the results of the present study indicate that elderly patients treated with CAPOX compared with CapMono report more sensory symptoms in the toes and feet that are known to persist long term, the addition of oxaliplatin might not be justified.

- It is of paramount importance to inform patients of the risk of developing neuropathic symptoms to enable patients to make informed decisions.

\section{Acknowledgments}

This work was supported by the Netherlands Organisation for Health Research and Development (Grant 113102004). The funding source had no involvement in the study design, collection, analysis, or interpretation of data, manuscript writing, or the decision to submit the report for publication.

\section{Disclosure}

The authors declare that they have no competing interests.

\section{References}

1. Yothers G, O'Connell MJ, Allegra CJ, et al. Oxaliplatin as adjuvant therapy for colon cancer: updated results of NSABP C-07 trial, including survival and subset analyses. J Clin Oncol 2011; 29:3768-74.

2. McCleary NJ, Meyerhardt JA, Green E, et al. Impact of age on the efficacy of newer adjuvant therapies in patients with stage II/III colon cancer: findings from the ACCENT database. J Clin Oncol 2013; 31:2600-6.

3. Kim CA, Spratlin JL, Armstrong DE, et al. Efficacy and safety of single agent or combination adjuvant chemotherapy in elderly patients with colon cancer: a Canadian cancer institute experience. Clin Colorectal Cancer 2014; 13:199-206.

4. Sanoff HK, Carpenter WR, Sturmer T, et al. Effect of adjuvant chemotherapy on survival of patients with stage III colon cancer diagnosed after age 75 years. J Clin Oncol 2012; 30:2624-34

5. Van Erning FN, Janssen-Heijnen MLG, Creemers GJ, et al. Recurrence-free and overall survival among elderly stage III colon cancer patients treated with CAPOX or capecitabine monotherapy. Int J Cancer 2016. http://dx.doi.org/10.1002/ijc. 30423 [e-pub ahead of print].

6. National Working Group on Gastrointestinal Cancers, 2015. Available at: www oncoline.nl. Accessed: September 11, 2015.

7. Saif MW, Wood TE, McGee PJ, et al. Peripheral neuropathy associated with capecitabine. Anticancer Drugs 2004; 15:767-71.

8. Beijers AJ, Jongen JL, Vreugdenhil G. Chemotherapy-induced neurotoxicity: the value of neuroprotective strategies. Neth J Med 2012; 70:18-25.

9. Ocean AJ, Vahdat LT. Chemotherapy-induced peripheral neuropathy: pathogenesis and emerging therapies. Support Care Cancer 2004; 12:619-25.

10. Farquhar-Smith P. Chemotherapy-induced neuropathic pain. Curr Opin Support Palliat Care 2011; 5:1-7.

11. Beijers A, Mols F, Dercksen W, et al. Chemotherapy-induced peripheral neuropathy and impact on quality of life 6 months after treatment with chemotherapy. J Community Support Oncol 2014; 12:401-6.

12. Beijers AJ, Mols F, Vreugdenhil G. A systematic review on chronic oxaliplatininduced peripheral neuropathy and the relation with oxaliplatin administration. Support Care Cancer 2014; 22:1999-2007.
13. Quasthoff S, Hartung HP. Chemotherapy-induced peripheral neuropathy. I Neurol 2002; 249:9-17.

14. Argyriou AA, Velasco R, Briani C, et al. Peripheral neurotoxicity of oxaliplatin in combination with 5-fluorouracil (FOLFOX) or capecitabine (XELOX): a prospective evaluation of 150 colorectal cancer patients. Ann Oncol 2012; 23: 3116-22.

15. Storey DJ, Sakala M, McLean CM, et al. Capecitabine combined with oxaliplatin (CapOx) in clinical practice: how significant is peripheral neuropathy? Ann Oncol 2010; 21:1657-61.

16. Sereno M, Gutierrez-Gutierrez G, Gomez-Raposo C, et al. Oxaliplatin inducedneuropathy in digestive tumors. Crit Rev Oncol Hematol 2014; 89:166-78.

17. Hershman DL, Lacchetti C, Dworkin RH, et al. Prevention and management of chemotherapy-induced peripheral neuropathy in survivors of adult cancers: American Society of Clinical Oncology clinical practice guideline. J Clin Oncol 2014; 32:1941-67.

18. Tofthagen C. Patient perceptions associated with chemotherapy-induced peripheral neuropathy. Clin J Oncol Nurs 2010; 14:E22-8.

19. Mols F, Beijers T, Vreugdenhil G, et al. Chemotherapy-induced peripheral neuropathy and its association with quality of life: a systematic review. Support Care Cancer 2014; 22:2261-9.

20. van de Poll-Franse LV, Horevoorts N, van Eenbergen M, et al. The patient reported outcomes following initial treatment and long term evaluation of survivorship registry: scope, rationale and design of an infrastructure for the study of physical and psychosocial outcomes in cancer survivorship cohorts. Eur J Cancer 2011; 47:2188-94.

21. Postma TJ, Aaronson NK, Heimans JJ, et al. The development of an EORTC quality of life questionnaire to assess chemotherapy-induced peripheral neuropathy: the QLQ-CIPN20. Eur J Cancer 2005; 41:1135-9.

22. Sangha $\mathrm{O}$, Stucki G, Liang $\mathrm{MH}$, et al. The self-administered comorbidity questionnaire: a new method to assess comorbidity for clinical and health services research. Arthritis Rheum 2003; 49:156-63.

23. Vissers PA, Mols F, Thong MS, et al. The impact of diabetes on neuropathic symptoms and receipt of chemotherapy among colorectal cancer patients: results from the PROFILES registry. J Cancer Surviv 2015; 9:523-31.

24. Steffens CC, Tschechne B, Schardt C, et al. Observational study of adjuvant therapy with capecitabine in colon cancer. Curr Med Res Opin 2015; 31:731-41.

25. Murugan K, Ostwal V, Carvalho MD, et al. Self-identification and management of hand-foot syndrome (HFS): effect of a structured teaching program on patients receiving capecitabine-based chemotherapy for colon cancer. Support Care Cancer 2016; 24:2575-81

26. Sibaud V, Dalenc F, Chevreau C, et al. HFS-14, a specific quality of life scale developed for patients suffering from hand-foot syndrome. Oncologist 2011; 16: 1469-78.

27. Clark AS, Vahdat LT. Chemotherapy-induced palmar-plantar erythrodysesthesia syndrome: etiology and emerging therapies. Support Cancer Ther 2004; 1:213-8.

28. Nagore E, Insa A, Sanmartin O. Antineoplastic therapy-induced palmar plantar erythrodysesthesia ("hand-foot") syndrome: incidence, recognition and management. Am J Clin Dermatol 2000; 1:225-34.

29. Wolf SL, Barton DL, Qin R, et al. The relationship between numbness, tingling, and shooting/burning pain in patients with chemotherapy-induced peripheral neuropathy (CIPN) as measured by the EORTC QLQ-CIPN20 instrument, N06CA. Support Care Cancer 2012; 20:625-32.

30. Schmoll HJ, Cartwright T, Tabernero J, et al. Phase III trial of capecitabine plus oxaliplatin as adjuvant therapy for stage III colon cancer: a planned safety analysis in 1,864 patients. I Clin Oncol 2007; 25:102-9.

31. Land SR, Kopec JA, Cecchini RS, et al. Neurotoxicity from oxaliplatin combined with weekly bolus fluorouracil and leucovorin as surgical adjuvant chemotherapy for stage II and III colon cancer: NSABP C-07. J Clin Oncol 2007: 25:2205-11.

32. Mols F, Beijers T, Lemmens V, et al. Chemotherapy-induced neuropathy and its association with quality of life among 2- to 11-year colorectal cancer survivors: results from the population-based PROFILES registry. J Clin Oncol 2013; 31: 2699-707.

33. Beijers AJ, Mols F, Tjan-Heijnen VC, et al. Peripheral neuropathy in colorectal cancer survivors: the influence of oxaliplatin administration. Results from the population-based PROFILES registry. Acta Oncol 2015; 54:463-9.

34. Boyette-Davis JA, Eng C, Wang XS, et al. Subclinical peripheral neuropathy is a common finding in colorectal cancer patients prior to chemotherapy. Clin Cancer Res 2012; 18:3180-7.

35. Mold JW, Vesely SK, Keyl BA, et al. The prevalence, predictors, and consequences of peripheral sensory neuropathy in older patients. J Am Board Fam Pract 2004; 17:309-18.

36. Gutierrez-Gutierrez G, Sereno M, Miralles A, et al. Chemotherapy-induced peripheral neuropathy: clinical features, diagnosis, prevention and treatment strategies. Clin Transl Oncol 2010; 12:81-91.

37. Kalsi T, Babic-Illman G, Fields P, et al. The impact of low-grade toxicity in older people with cancer undergoing chemotherapy. Br J Cancer 2014; 111:2224-8. 